
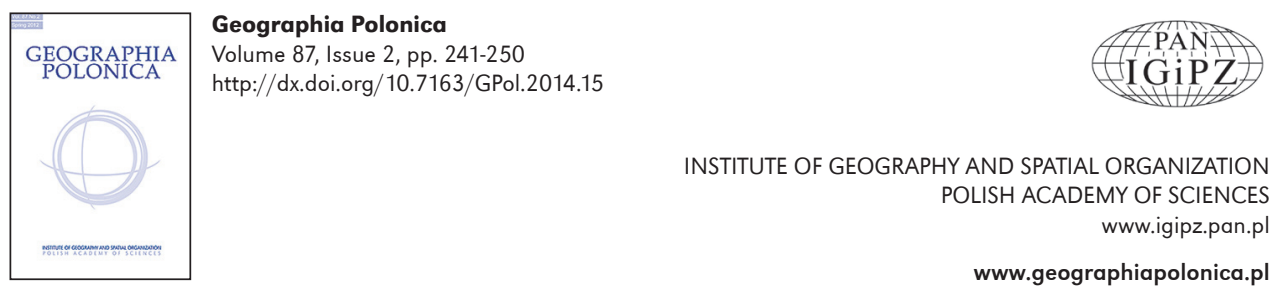

\title{
A WORLD WITHOUT GIS? POST-GIS FUTURES FOR THE NEW MILLENNIUM
}

\author{
Francis Harvey \\ Chair of the Commission on Geographical Information Science \\ University of Minnesota \\ Department of Geography, Environment and Society \\ MN 55455, Minneapolis: USA \\ e-mail: fharvey@umn.edu
}

\begin{abstract}
We stand on the cusp of an era when anyone with internet access can make a map. With six billion mobile phone subscribers and 2.3 billion internet users will GIS play much of a role in how make and use maps? This paper begins with this question and explores some of the dimensions of how GIS will change in a new world a world where GIS is integral to countless online activities and hence disappears from most uses. This is world not without GIS, but a post-GIS world of ubiquitous location technologies. While many of these developments, they have negative potential and the article points to areas to consider carefully.
\end{abstract}

\section{Key words}

GIS • information society $\bullet$ internet $\bullet$ data-driven science $\bullet$ ubiquitous computing

\section{Introduction}

The time is here when anyone with internet access can make a map. When maps, both good and bad, are so ubiquitous that people no longer often notice maps. With six billion mobile phone subscribers and 2.3 billion internet users will GIS play much of a role in how make and use maps? GIS certainly has laid the foundation for this ubiquity of maps and geographic information. As Ron Abler puts it, GIS has had impacts similar to the impacts of the microscope (Abler 1991).
And just as microscopes have become ubiquitous and disappear into classrooms and laboratories, is it possible that GIS 'suffers' the same fate? While no one can predict the future, the position of this article is that indeed GIS in the coming years will undergo an analogous development. While in the future of GIS we might recognize data and the use of computers, and maybe even parts of the software interfaces, GIS will become an integral part of computing infrastructures. In a post-GIS era of discovery GIS will be everywhere and so disappear in the senses most 
of us know it now. According to famous user interface designer and theorist Norman, this is the most success any invention can achieve (Norman 1993)

Already we know the world is changing but the variability and scope are daunting, even overwhelming. Yet, for most of us the future is already there in some shape or form. After centuries of looking beyond the horizon for new discoveries, with growing abilities through ubiquitous computing, people are realizing that while discoveries may be made far away and from the unknown, many discoveries can be made among the many unknowns and lesser knowns for us both near and far. In this sense, perhaps the biggest future discoveries of geography are in our neighborhoods, cities, and regions. What certainly is different is that computer networks, ubiquitous computing, and the internet of things are the foundations for this new era of discovery. And location technologies are also central. Today, most people on planet Earth can make a map or orientate themselves with location technologies, starting with the over one billion (October 2011) people who have downloaded Google Earth, the millions of Bing!, Yahoo!, World Wind users, the 6 billion mobile phone subscribers (World Bank 2012), and the millions of GIS users. Location-based computational approaches are becoming accessible to the majority of the earth's inhabitants. Human society is moving on from the GIS era. Yet, the proverbial GIS cup is not really half full, it is really, at this point, half empty with potential maps and geographic knowledge. Although GIS has had a vast impact on the world, much of its uses have simple locationbased systems capacity arising through text messages and cell tower triangulation. This is modest, but already a huge leap in location technology compared to abilities just twenty years ago when mobile phones found most of their adoption in wealthy countries of the first world. Through the ongoing realization of technological innovations, including the application of Artificial Intelligence (Al) tools, we can expect in the future to see further advances. While all people on the planet may not all be able to make maps, and those who can are not always thinking of making maps, anyone with access to mobile phones certainly can use location technologies.

While new discoveries can be made both near and far afield, the key difference from past eras, is that with location technologies, the new era of discovery is the discovery of the previously unknown, or unknown unknowns (Dowd 2013). It may involve discovering the history of a neighborhood that reveals the presence of a hazardous waste site long forgotten, the discovery of animal migration routes, the discovery of how under-represented groups utilize public transportation, or the discovery of one of the world's heritage sites. Further, it will be different then all past eras of discovery, because at no other time in human history have the capabilities of information technologies ever been so readily available to the majority of people. And Gl technologies are central to this era. We see that already in Volunteered Geographic Information (VGI), projects in which citizen cartographers volunteer their time and knowledge to contribute geographic information to countless civic projects (Goodchild 2007). The internet has and still is transforming the way maps are made and people share geographic information. Some projects are global in scope; some are local. All involve a good measure of discovery, the fascination with learning and knowing what was previously unknown. Many of these projects also follow concepts of citizen science (Haklay et al. 2008). Drawing on these possibilities, other scientists are developing approaches to use these data sources to make our cities 'smarter' and reduce traffic congestion, address environmental issues, and improve the quality of life for now and the future (Roche et al. 2012). Scientists are also drawing on concepts of large data sources to develop computerized approaches to augment existing technologies and arrangements (Walcott-Bryan et al. 2012).

As is true in all eras, not all developments are always seen from a positive light. We should also think about where we tread. As with any wide-spread innovation, e.g. telephones, 
television, cameras, automobiles, the developments and negotiations of new technologies are an involved process that engages multiple groups in society. Dystopian perspectives become vehicles for channeling concerns and anxieties. Countering fear-mongering means speaking to concerns about the use of surveillance technologies (Elwood \& Leszczynski 2011) and potentials for merging data sets to circumvent anonymity (Harvey 2014) among the many issues that raise concerns. The range of uses and concerns points to in importance of treating maps as opinion pieces (Brotton 2012) and the already apparent use of location technology to provide ubiquitous orientation and ubiquitous surveillance. What GIS has begun to make possible, is already changing the world. We will, and we have in some cases, experienced future coordination of physical space with digital space (Kurgan 2013). Indeed, as Gibson suggests, the future is already here, it's just unevenly distributed (Gibson 2012).

\section{Uneven presents and uneven futures: What do we know?}

The future maybe unevenly distributed, but much is of the present remains unknown, so sometimes what we think is just now becoming possible in fact may already be reality. Our future realities also will be different and beyond what we know we know. Our use of location technologies will continue to rely on cartographic representation and human facilities of interpretation. But we should also think of the unknown unknown, the socalled black swan case (Taleb 2007) in thinking about what discovery can mean beyond the internet and web, past the consumer orientation of most online activities, beyond the geoweb, far beyond the way the world is and was, and even beyond ourselves. There are many examples for the ways that our contemporaries reach beyond what we find and point to potentials. Unrelated to location technologies, but one of the more practical sites to find exciting hybridization of current technologies is the Ikea Hackers site (ikeahackers.net). Thousands of examples show how to hybridize and extend off-the-shelf Ikea products to fit new demands. One of the most provocative examples to recently appear is the hacked children's bicycle, Draisienne, made from two Frosta stools with pliers, a drill, a metal saw, and a 3D printer by Samuel Bernier and Andreas Bhend in Paris over 2.5 days (http:// www.coroflot.com/samuelbernier/Hack-ofIKEAs-Frosta-stool). And even though geographers may be quite a conservative group over-all when it comes to creative hacking of mapping technologies, thousands of examples from compatriots point to ways that mapping and maps can be hacked. From Solnit's Infinite City (Solnit et al. 2010) to the Atlas of Radical Cartography (Mogel \& Bhagat 2008) and many more, we can see how NeoGeography is a milestone in the shifting role of location technologies, but much more can and should be expected as information technologies become ubiquitous.

But before jumping in feet first to consider post-GIS futures let's though consider what do we know? When looking to the future, we still need to reflect on what we know and think about past successes and past limits. Considering GIS, any history, for example recent work by Sui, Couclelis, Wright, and others (Couclelis 2012; Sui 2012; Wright 2012) that points out numerous limits in GIS technology demonstrates an information processing architecture concept for working with location information moving with astonishing successes from the industrial production of map series by national mapping organizations (Chrisman 2006) to a completely altered world in which geospatial is potentially a part of every thing. GIS was part of a big shift in the information age moving from resolving technical aspects to the enablement of critical spatial thinking. And that is without a guarantee of success: many users of satellite navigation systems who fail to update their databases become aware of this only through bad experience (Brown et al. 2010, 2012) alone and unfortunately not too few accidents.

Some changes of the post-GIS era already are definitely afoot: Google Earth is many times more widely used then even the most 
successful GIS. The ubiquity of sensors and devices with computational capabilities and connectivity to make sense of geographic relationships have supported in the first phase of innovation a raft of innovative location-based applications. The deluge of smartphone app points to the abilities of creative programmers to develop means for us to turn physical location and virtual connections and access into usually exciting and innovative means of discovery, but at times unsettling and even outright disturbing services. Which changes will become the basis for new rounds of innovative applications remains to be seen. We though should steel ourselves to the deep-reaching changes that are certain to continue. Already, $40 \%$ of the companies in the Fortune 500 in 2000 were no longer there in 2010 (Solis 2012). We should expect similar changes to government and private actors in the GIS field.

Given the wide-reaching nature of these changes also we should remind ourselves that none of us holds a compass to guide us into the futures. We need to be ready for changes and discoveries not only in applications, but in the underlying technology itself. Perhaps one of the most significant changes that we will see in the next years is the increased resolution of Global Positioning System/Global Navigation Satellite System (GPS/GNSS) limits also for indoor use and challenging environments by the complementary use of timing and inertial measurement units, such as recently revealed by Defense Advanced Research Projects Agency (DARPA), that in the space of 10 cubic millimeters holds three gyroscopes, three accelerometers, and a master clock (Lecher 2013). Without a reliable compass, we need to think about discovery as a time for exciting innovations but also for disruptive activities.

\section{GIS is dead, long live GIS!}

One thing that may frighten many is the perspective that GIS appears to be on its death bed. Of course, not in Marc Antony's sense, when he says in Shakespeare's play Julius
Caesar, "I come to bury Caeser, not to praise him", but in the sense of technological innovation cycles that have run their course. GIS is now becoming one of many location technologies, often indecipherable in detail from other types of technology and increasingly categorized to fit specific purposes (Star 1995, 1999; Bowker \& Star 1999; Chrisman 2005). Following on Norman's work, we should not mourn nor worry about these developments, but instead celebrate the many, some might say, countless positive impacts of GIS technology as it becomes part of everyday activities, disappearing effectively from concern (Norman 1993).

The millions of GIS deployments, used daily, transcend text book definitions of technology, as each instance involves a range of adaptations to assure it functions well with other technologies, people, and institutions. We see that in the closely related development of Spatial Data Infrastructures (SDI) from centralized strategies to create and support inter-departmental data sharing to become distributed and service-orientated approaches (Harvey et al. 2012). Or as Ed Parsons recently expressed, GIS is going from being a technology for applications, to becoming part of ubiquitous computing with "a bit of geospatial in everything."

In the post-GIS era, following Norman and others GIS is becoming part of the infrastructure. What does that mean? Hendriks, Dessers and van Hootegem (Hendriks et al. 1998) address the ambiguity of the term using a system-theoretical approach and pointing to the need to enhance considerations of the role of people in SDI. Nedovic-Budic and Pinto (2000), Harvey and Chrisman (1998), Erik de Man (2006), De Paoli and Miscione (2011), and others have addressed similar impulses and draw on concepts and theories from science and technology studies and information studies to guide empirical studies and develop insights into the roles of people. Work by Star and Bowker that analyzes the concept of infrastructure (Star \& Ruhleder 1996; Star 1999; Bowker 2005) highlights the importance of considering the multiple human 
and nonhuman dimensions of infrastructure as the foundation for change in the information age geography.

\section{Data-driven science and post-GIS}

We seem to have become used to the notion that immeasurable amounts of data are collected every day, almost constantly on the environment and about people. Sensors are everywhere. Abilities to access and use this information are fundamentally altering science. Considering the growing ubiquity of computational devices (Bell \& Gray 1997), Gray considers the changing roles and activities of science in data-intensive computing. It is a broad concept of computing for developing and refining theories in science and support the whole research cycle. Data exploration science, or eScience, consists of three primary activities: capture, curation, and analysis. Following Gray, the so-called fourth paradigm must consider the broad range of data scientists, engineers, and experts involved in the successful management of digital data. Beyond the critical attention given infrastructure aspects, the shift to the fourth paradigm is what indeed critically distinguishes the post-GIS era from the GIS era. In considering the development of computational capabilities more broadly, Gray describe the previous third paradigm as the era dominated by computational approaches focused on simulating complex phenomena. Global change modeling, regional flood forecasting, scenario building, etc are some of the rich examples with many connections to GIS with countless examples that show the innovative scientific work done with GIS. With the growing amounts of data we now have available the shift to the fourth paradigm is taking place of necessity. Science is changing. The theoretical models grow too complicated to solve analytically and people started using simulations. Simulations generate a lot of data and now most scientists are no longer observing the world, but 'looking' through data-based simulations that present information on their computers (MacEachren 1995;
MacEachren et al. 2005). Computational ecology, medicine, biology, etc all represent vibrant fields that apply computer science techniques and technologies (Wing 2006).

With all the data being created today, 2.5 quintillion bytes every day (IBM 2014) the need for information management and sustainable organization of infrastructures capable of supporting data-intensive computing. Standardized formats for data interchange such as the Hierarchical Data Format (HDF) and support for distributed processing through SpatialHadoop, help deal with the challenges. Fundamentally however, institutions are changing and adapting the technology to fit their circumstances and established management cultures. As Gray and others point out, we can see this occurring in scholarly publishing which is moving to greater open access of articles and also data (Ahlqvist et al. 2013).

For post-GIS technologies to support these changes in science, GIS, conceived of in an era dominated by the industrial age production of paper maps, and since evolved to support complex analytics and simulations, needs to evolve beyond its existing infrastructural organization. While in a transition still (Sui 2012) with much changing, it seems GIS has become an integral component of government and private institutions. Yet, it seems that the new ways to handle geographic information, signaled in the concept of NeoGeography (Turner 2006), are already pointing to post-GIS technological and institutional architectures.

\section{Post-GIS in the age of ubiquitous computing}

Considering the next-generation of geographic information technologies, several characteristics of successful technologies and institutions will mark future developments in the age of ubiquitous computing and dataintensive science. This paper points to several key aspects arising in the increasing abilities to merge interactions in the digital and physical worlds and strategies to create sustainable social coordination strategies. 
A key aspect of the changes is the potential to create dynamic connectivity in multiple dimensions. Discoveries of the unknown knowns and unknown unknowns benefit from networked information technology to transcend physical space. We are no longer bound by spatial proximity to engage rich information with groups of people, nor by industrial age modes of information publishing. Widely used social networking applications make it already possible to connect to multiple interaction spaces simultaneously and, limited it seems largely only by our abilities to multi-task, to engage with people far beyond the scope of our immediate physical environment. This aspect is directly connected to increasing network capacity for smoothing the illusive divide between what we know of the world and what is. As the physical and virtual worlds of computing increasingly merge through discoveries, new potentials, relationships, and new vulnerabilities arise in the networked digital infrastructures that increasingly define what we know about the world around us. Finally, as Gray points out, and Goodchild and others (Gould et al. 2008) consider, the increasing amounts of data lead to intensively collaborative large group research. Indeed, social coordination from the individual, institutional, and international level seem more and more a key foundation for science and government activities.

The development of these discoveries will of course not come by themselves. Many will come through commercial applications and services, but not alone. Teaching remains a key vehicle to develop intellectual capabilities. Yet, the changes, as we note in higher education around the world alone in the recent proliferation of Massive Open Online Courses (MOOCs) are themselves evolving as people explore abilities to use abilities of ubiquitous computing to learn to teach and teach to learn in different ways, which are not without detractors and concerns, but still seem poised to point to new modes of education delivery that could change many aspects of the educational systems developed in the industrial era.
Post-GIS era changes are already taking hold in education. Edsall (2013) in a recent presentation connects Gray's fourth paradigm to crowd-sourcing of data and gamification showing not only the great potential for engaging students, but turning learning into a wider reaching pedagogy that starts and continues discoveries, also beyond education itself and helping define different ways to grasp relationships to others and place. This concept is reflected on the development of spatial citizenship (Gryl \& Jekel 2012). While the approaches address issues in helping students learn to use GIS at one level, the more important aspect is going beyond technical interests and related instrumental knowledge. In this manner, this concept also provides a robust didactical framework for helping tomorrow's knowledge workers come to grips with the evolving technological landscape and develop the critical thinking capacities to support later contributions to their fields and help give meaning to their lives.

The spatial dimensions of space have been the focus of these engagements and offer a critical foundation for considering the fundamentals, principles, and concepts of post-GIS, including key activities of GeoCoding, issues of accuracy, and the central role of coding in these technologies. And because of the central roles of spatial analysis and cartographic visualization remain, teaching of fundamental principles provides keys to the possibilities of the future.

\section{Some central issues of the post-GIS era}

The ubiquity of computing infrastructures around the world open potentials for a new era of discovery in global science and geographic information technologies. Most of all, the discoveries will be near, not distant and involve finding out those things that have been hidden, but were so near. The changes this paper summarizes in terms of a vision for a post-GIS era are coming. How they will be called and what they mean specifically are important issues for us to consider now before 
it is too late. We may already have heard of the idea of the 'preemptive governing' idea coming from well-intentioned professionals at the forefront of the ubiquitous computing (Howard 2013) and other approaches to utilize ubiquitous computing data data-intensive science to help create a better world. To develop, or in some cases, even reflect on the potentials, we need well educated scientists who can ground their decisions in their far-reaching responsibility and robust understanding of the technologies.

Here we might move to deepen scientific geography's engagements through more consideration of the work of Levinson, who in his book The Soft Edge develops a framework for considering past developments of media technology and carefully thinking about future developments. A key element is consider what Levinson calls the 'four-way square dance' of vision and sound through the camera (extension of vision across time), the telegraph (extension of vision across space), the phonograph (extension of sound in time), and the telephone (extension of sound across space) (Levinson 1997). The growing ubiquity of geographic information access and online maps surely points to possible current and future integrations of these four dimensions.

The resulting combinations of possibilities and extension of GIS-related media involve fundamental anthropomorphic changes. In this sense the four key characteristics of a post-GIS world offer us starting points to consider central issues in research and teaching. In summary, the four characteristics are:

- connectivity in multiple dimensions,

- increasing merging of physical and virtual worlds,

- networked digital infrastructures for people and things,

- intensively collaborative large group research in science and similar developments in industry and government.
In the age of ubiquitous computing, the increasing merging of digital and physical worlds, location technologies are beginning to be augmented, altered, or even replaced. Distributed programming, which is already possible using Amazon's Mechanical Turk, device programming, data programming, democratized computing, and dangerous computing (Dumbill 2013) will become key domains in which location technology specialists can have lasting impact.

With these changes research and teaching challenges abound, but have and will vary. At universities we have already begun laying the foundation for these changes (Fisher 2012; Harvey et al. 2013). We see in these projects too that the future is already here, but also in the university it's still unevenly distributed. The post-GIS era is part of these many changes. In summary, a world without GIS isn't really without the capabilities of GIS, but these capabilities will be used so differently, that we won't be able to recognize today's GIS any more.

\section{Acknowledgements}

Many people have discussed with me the issues that this paper takes up. I wish to thank Dan Sui, Werner Kuhn, Nadine Schuurman, Adam Iwaniak, Serena Coetzee, Antony Cooper, and Dawn Wright in particular. I also want to thank colleagues from the University of Minnesota's U-Spatial project for their contributions to laying the foundation for spatial research in tomorrow's universities. Special thanks is due to participants of the z_GIS GI_Forum in July 2013 for their many comments and queries on an earlier version of these issues that influenced the development of this paper. Of course, any errors or distortions in this paper remain my responsibility alone. 


\section{References}

Ahlqvist O., Harvey F., Ban H., Chen W., Fontanella S., Guo M., Singh N., 2013. Making journal articles 'live': Turning academic writing into scientific dialog. GeoJournal, vol. 78, no. 1, pp. 61-68.

BeLL G., Gray J., 1997. The revolution yet to happen [in:] P.J. Denning, R.H. Metcalfe (eds.), Beyond calculation: The next fifty years of computing. New York: Springer Verlag.

BROTTON J., 2012. A history of the world in twelve maps. London: Penguin Books.

Bowker G.C., 2005. Memory: Practices in the sciences. Cambridge (Massachusetts): MIT Press.

Bowker G.C., Star S.L., 1999. Sorting things out. Classification and its consequences. Cambridge (Massachusetts): MIT Press.

Brown M., Harding J., Sharples S., 2010. Exploring the usability of geographic information: A grounded theory analysis [in:] Proceedings of the GIS Research UK 18th Annual Conference. University College London, pp. 417-422.

Brown M., Sharples S., Harding J., Parker C.J., Bearman N., Maguire M., Forrest D., HakLAY M., JACKSON M., 2012. Usability of geographic information: Current challenges and future directions. Applied Ergonomics, vol. 44, no. 6, pp. 855-865.

Chrisman N., 2005. Full circle: More than just social implications of GIS. Cartographica: The International Journal for Geographic Information and Geovisualization, vol. 40, no. 4, pp. 23-35.

Chrisman N., 2006. Charting the unknown. How computer mapping at Harvard became GIS. Redlands (California): ESRI Press.

Couclelis H., 2012. Climbing on a milestone for a better view: Goodchild's 'Geographical Information Science' paper as vantage point and ground for reflection. International Journal of Geographical Information Science, vol. 26, no. 12, pp. 2291-2300.

De Paoli S., Miscione G., 2011. Relationality in geolT software development: How data structures and organization perform together. Computers, Environment and Urban Systems, vol. 35, no. 2, pp. 173-182.

Dowd M., 2013. A mad Tea Party. The New York Times, published 12 October 2013.
DUMBILL E., 2013. The future of programming: Unraveling what programming will need for the next 10 years. Radar. Insight Analysis and Research about Emerging Technologies, published 11 January 2013.

EDSALL R., 2013. Volunteered geographic analysis: Crowd-sourcing hypothesis generation with interactive Internet mapping applications. Paper read at Annual Meeting of the Association of American Geographers, at Los Angeles, CA, 9-13April 2013.

Elwood S., LeszCZYNSKI A., 2011. Privacy, reconsidered: New representations, data practices, and the geoweb. Geoforum, vol. 42, no. 1, pp. 6-15.

ERIK dE MAN W.H., 2006. Understanding Sdi: Complexity and institionalization. International Journal of Geographical Information Science, vol. 20, no. 3, pp. 329-43.

FISHER T., 2012. Place-based knowledge in the digital age. ArcNews. Esri. Fall 2012, vol. 34, no. 3.

GIBSON W., 2012. Distrust that particular flavor. New York: G.P. Putnam's Sons.

GoodCHILD M.F., 2007. Citizens as sensors: The world of volunteered geography. GeoJournal, vol. 69, no. 4, pp. 211-221.

Gould M., Craglia M., Goodchild M.F., Annoni A., Camara G., Kuhn W., Mark D., Masser I., Maguire D., Liang S., Parsons E., 2008. Nextgeneration digital earth: A position paper from the Vespucci initiative for the advancement of Geographic Information Science. International Journal of Spatial Data Infrastructures Research, vol. 3, pp. 146-167.

GRYL I., JeKEL T., 2012. Re-centring geoinformation in secondary education: Toward a spatial citizenship approach. Cartographica: The International Journal for Geographic Information and Geovisualization, vol. 47, no. 1, pp. 18-28.

Haklay M., Singleton A., Parker C., 2008. Web Mapping 2.0: The Neogeography of the Geoweb. Geography Compass, vol. 2, no. 6, pp. 2011-2039.

Harvey F., 2014. We know where you are. And we're more and more sure what that means [in:] K. Pimple (ed.), Emerging pervasive information communication technology (PICT) Berlin: Springer Verlag [in print].

Harvey F., Chrisman N.R., 1998. Boundary objects and the social construction of G/S technology. 
Environment and Planning A, vol. 30, no. 9, pp. 1683-94.

Harvey F., Iwaniak A., Coetzee S., Cooper A.K., 2012. Sdi past, present and future: A review and status assessment [in:] A. Rajabifard, D. Coleman (eds.), Spatial enabling government, industry and citizens. Needham (Massachusetts): GSDI Association Press, pp. 23-38.

Harvey F., Kne L., Manson S., 2013. U-Spatial: A consortium for the spatial university. Arc News, vol. 34, no. 4, pp. 1-6.

Hendriks P.H.J., Dessers E., van Hootegem G., 2012. Reconsidering the definition of a spatial data infrastructure. International Journal of Geographic Information Science, vol. 26, no. 8, pp. 1479-1494.

Howard A., 2013. On the power and perils of "preemptive government": Stephen Goldsmith on the potential of urban predictive data analytics in municipal government. O'Reily: Data, published 28 February 2013.

IBM, 2014. IBM big data and analytics platform. http://www-01.ibm.com/software/data/bigdata/ [12 January 2014].

KuRGAN L., 2013. Close up at a distance: Mapping, technology, and politics. Cambridge (Massachusetts): MIT Press.

LECHER C., 2013. From DARPA, a navigational device that fits on a penny and works when GPS doesn't. Australian Popular Science, published online 11 April 2013.

LEVINSON P., 1997. The soft edge: A natural history and future of the information revolution. London-New York: Routledge.

MacEachren A.M. 1995. How maps work. Representation, visualization, design. New York: Guilford Press.

MacEachren A.M., Cal G., Sharma R., Rauschert I., Brewer I., Bolelli L., Shaparenko B., FuhrMANN S., WANG H., 2005. Enabling collaborative geoinformation access and decision-making through a natural, multimodal interface. International Journal of Geographical Information Science, vol. 19, no. 3, pp. 293-317.

Mogel L., Bhagat A. (eds.), 2008. An atlas of radical cartography. Los Angeles: Journal of Aesthetics \& Protest Press.

Nedovic-Budic Z., Pinto J.K., 2000. Information sharing in an interorganizational GIS environment. Environment and Planning B. Planning and Design, vol. 27, no. 3, pp. 455-474.

Norman D.A., 1993. Things that make us smart: Defending human attributes in the age of the machine. Reading (Massachusetts): Addison-Wesley.

Roche S., Nabian N., Kloeckl K., Ratti C., 2012. Are 'smart cities' smart enough [in:] Global Geospatial Conference 2012 "Spatially Enabling Government, Industry and Citizens". Quebec City, Canada, 14-17 May 2012, pp. 215-235.

Solis B., WebBer A., 2012. The rise of digital influence $A$ "how-to" guide for businesses to spark desirable effects and outcomes through social media influence. San Mateo (California): Altimeter Group.

Solnit R., Pease B., Siegel S., 2010. Infinite city: A San Francisco atlas. Berkeley (California): University of California Press.

STAR S.L., 1995. The politics of formal representations: Wizards, gurus, and organizational complexity [in:] S.L. Star (ed.) Ecologies of knowledge: Work and politics in science and technology. Albany: State University of New York Press.

STAR S.L., 1999. The ethnography of infrastructure. American Behavioral Scientist, vol. 43, no. 3. pp. 377-391.

Star S.L., Ruhleder K., 1996. Steps towards and ecology of infrastructure: Design and access for large-scale collaborative systems. Information Systems Research, vol. 7, no. 1, pp. 111-134.

SuI D., 2012. Beyond mathematics and the deflationary turn: Fundamental concepts in Giscience - to whom and for what ends? [in:] F. Harvey (ed.), Are there fundamental principles in Geographic Information Science? Tobler Lecture Event 2012, Seattle: CreateSpace Independent Publishing Platform.

TaleB N.N., 2007. The black swan: The impact of the highly improbably. London: Penguin Books.

TURNer A., 2006. Introduction to neogeography. Sebastopol (California): O'Reilly Media.

Walcott-Bryan, A., Kaess M., Johannsson H., LeONARD J.J., 2012. Dynamic pose graph Slam: Long-term mapping in low dynamic environments [in:] Intelligent Robots and Systems (IROS), 2012 IEEE/RSJ International Conference, pp. 1871-1878. 
WING J.M., 2006. Computational thinking. Communications of the ACM, vol. 49, no. 3 , pp. 33-35.

WorLD BANK, 2012. Mobile phone access reaches three quarters of planet's population. World Bank. News, published 17 July, 2012.
WRIGHT D., 2012. Theory and application in a postGISsystems world. International Journal of Geographical Information Science, vol. 26, no. 12, pp. 2197-2209. 